\title{
Second drug-eluting stent implantation versus coronary artery bypass grafting in treatment of young patients with left main and/or multivessel coronary disease
}

\section{Xue Chen}

Capital Medical University Affiliated Anzhen Hospital

Xuehui Zhang

Capital Medical University Affiliated Anzhen Hospital

\section{Yunfeng Yan}

Capital Medical University Affiliated Anzhen Hospital

\section{Xin Zhao}

Capital Medical University Affiliated Anzhen Hospital

\section{Maoxiao Nie}

Capital Medical University Affiliated Anzhen Hospital

\section{Tingting Feng}

Capital Medical University Affiliated Anzhen Hospital

\section{Zhe Liang}

Capital Medical University Affiliated Anzhen Hospital

\section{Quanming Zhao ( $\nabla$ zhaoquanming1@sina.com )}

Capital Medical University Affiliated Anzhen Hospital https://orcid.org/0000-0003-3457-4953

\section{Research article}

Keywords: Coronary artery bypass graft; Left main disease; Multivessel disease; Percutaneous coronary intervention

Posted Date: October 4th, 2019

DOI: https://doi.org/10.21203/rs.2.14617/v2

License: (c) (i) This work is licensed under a Creative Commons Attribution 4.0 International License. Read Full License 
Version of Record: A version of this preprint was published at Journal of Interventional Cardiology on April 21st, 2020. See the published version at https://doi.org/10.1155/2020/6736704. 


\section{Abstract}

Background Many studies have compared outcomes of coronary artery bypass graft (CABG) and percutaneous coronary intervention (PCl) for complex coronary artery disease (CAD). However, no trials have focused on young patients ( $<45$ years) with complex CAD. We conducted a retrospective evaluation to compare the outcomes of a 2nd drug-eluting stent and CABG in young patients with LM or three-vessel disease. Methods In the young patients with complex CAD who underwent PCI or CABG, Kaplan-Meier analysis and Cox regression before and after propensity-score matching were used to compare major adverse cardiac and cerebrovascular events (MACCE), including myocardial infarction (MI), stoke, death and repeat revascularization. Results During the follow-up, MACCE occurred in $20.5 \%$ of patients in the $\mathrm{PCl}$ group and $8.6 \%$ in the CABG group (hazard ratio [HR]: $3.263,95 \%$ confidence interval [CI]: 1.379 to $7.722, p=0.007)$. Repeat revascularization occurred more frequently in the PCI group (18.9\% vs. $3.7 \%$ respectively, HR: $6.968,95 \% \mathrm{Cl}: 2.036$ to $23.842, \mathrm{p}=0.002)$. There were no significant differences in other endpoints. After propensity-score matching, no conclusions were changed. Conclusions In young patients with LM or three-vessel disease, $\mathrm{PCI}$ showed a higher incidence of MACCE, which was mainly driven by repeat revascularization. However that did not translate into hard endpoints differences. Therefore, $\mathrm{PCl}$ is an alternative treatment to $C A B G$ in young patients with complex CAD.

\section{Background}

The left main (LM) disease and three-vessel disease are complex coronary artery disease (CAD), whose treatment is more difficult. Coronary artery bypass graft (CABG), as an effective treatment for CAD, has introduced more than 50 years which, is currently the preferred modality to treat complex CAD (13). However, over the last twenty years, there have been significant advances in percutaneous coronary intervention $(\mathrm{PCl})$, from the era of balloon angioplasty and subsequently bare-metal stents to drug-eluting stents (DESs) (4-6). With improving technology and technique of $\mathrm{PCl}$, such as adjunctive antithrombotic drugs, periprocedural management and the experience of interventional cardiologists, research has increasingly focused on more complex diseases, such as disease and multivessel disease.

The latest European Society of Cardiology (ESC) and European Association for Cardio-Thoracic Surgery (EACTS) guidelines(7) recommend CABG (class I, level A) for complex CAD both LM disease and threevessel disease regardless of anatomic complexities of coronary arteries. However, $\mathrm{PCl}$ is an alternative in the case of LM disease and three-vessel disease if the SYNTAX score is $\leq 22$ (class I, level A); if the SYNTAX is $>22$, it would be inferior for LM disease and three-vessel disease (class II or III, level A or B). Even so, along with the rapidly progressing technology, an increasing number of patients and cardiologists prefer $\mathrm{PCl}$ over $\mathrm{CABG}$, according to many trials. Several trials have reported that $\mathrm{PCl}$ is noninferior to CABG in patients with LM disease (8) or multivessel disease (9). On the other hand, many trials have suggested CABG might provide better clinical outcomes than PCI (10-12).

In view of the younger characteristics of CAD patients and the likelihood of graft failure, and considering that $62 \%$ of patients will have recurrent ischemia by 15 years postoperatively (13), it is essential to 
consider the risk/benefit ratio of $\mathrm{PCl}$ and $\mathrm{CABG}$ for $\mathrm{LM}$ and three-vessel disease, weighing procedural invasiveness and the associated short-term complications against long-term event rates of death, myocardial infarction (MI), stoke, and repeat revascularization, and improvements in health-related quality of life (14). Therefore, we hypothesize that PCI should be performed at an early age if possible to alleviate symptoms to provide another choice for advanced illness. We conducted a retrospective evaluation to compare real world outcomes between CABG and PCl using second-generation DESs in young patients with LM disease or three-vessel disease.

\section{Methods}

This was a single-center retrospective study comparing $\mathrm{PCl}$ with 2nd DES and CABG in young patients with LM and three-vessel disease. We performed a review of all young patients who underwent diagnostic coronary angiography, and PCI or CABG at Beijing Anzhen Hospital from January 2015 to December 2016. We screened these patients and enrolled them if they had LM and/or three-vessel disease and underwent $\mathrm{PCl}$ with a 2nd-generation DES or CABG. The patients who had previously undergone $\mathrm{PCl}$ were also included in our study. Patients were excluded if: 1) they did not suffer from LM or three-vessel disease; 2) they had acute myocardial infarction (MI), either ST segment elevation or non-ST segment elevation; 3 ) they underwent concomitant valvular or aortic surgery; 4) they had previous CABG surgery; and 5) patients were unable to receive both procedures or did not want to.

In our trial, the revascularization strategy was determined by physicians' and/or patients' preferences, on the basis of hemodynamic conditions, anatomic factors, vessel size, the presence of comorbidities and quality of arterial and/or venous conduits grafts fit.

All PCI procedures were performed according to current standard interventional guidelines. Antiplatelet therapy and periprocedural anticoagulation followed standard regimens. All patients received $300 \mathrm{mg}$ of loading dose aspirin and/or clopidogrel (or 180 ticagrelor) before the procedure. After $\mathrm{PCl}$, all patients were recommended $100 \mathrm{mg} /$ day aspirin indefinitely and $75 \mathrm{mg} /$ day clopidogrel or ticagrelor $90 \mathrm{mg}$ twice daily for at least 1 year. There was no restriction on the second-generation DESs.

The bypass graft revascularization was performed with standard bypass techniques. A normal midline sternotomy incision was used to expose the heart and both on-pump and off-pump surgeries were performed at the preference of the surgeon. The internal thoracic artery was preferred for bypass of the left anterior descending artery. After CABG, medications were given according to the guidelines or the preference of the surgeon.

Patient data on demographics, comorbid conditions, laboratory echocardiography, procedures and so on were collected via chart review. The ethics committee at our hospital (Beijing Anzhen Hospital) reviewed our study protocol and approved the use of clinical data for the study. Because of the retrospective nature of our trial, the need for patient informed consent was waived. Follow-up and information on the clinical status were achieved by clinical visits and telephone interviews. 
The primary endpoint in our trial was major adverse cardiac or cerebrovascular events (MACCE), a composite of all-cause death, stroke, myocardial infarction (MI), and repeated revascularization. Secondary endpoints were the individual occurrence of all-cause death, stoke, $\mathrm{Ml}$ and repeat revascularization. Deaths were considered cardiac unless unequivocally noncardiac. Stoke was defined as a focal neurological deficit of central origin lasting $>24 \mathrm{~h}$, confirmed by a neurologist and computed tomography or magnetic resonance imaging. MI was defined as a creatine-kinase-MB level $>50 \mathrm{ng} / \mathrm{ml}$ or the appearance of new Q-waves or ST segment elevation $>2 \mathrm{~mm}$, on the electrocardiogram which were confirmed by a veteran cardiologist. Repeated revascularization in our trial was any revascularization that was performed on any vessel by PCl or CABG.

Young patients were defined as $<45$ years old according the World Health Organization (WHO). The lesion of each vessel, including its main branches (diameter $\geq 1.5 \mathrm{~mm}$ ) was defined as $\geq 50 \%$ stenosis. Multivessel disease or three-vessel disease was $\geq 50 \%$ stenosis in all three epicardial coronary arteries, consisting of the left anterior descending artery (LAD), left circumflex artery (LCX) and right coronary artery (RCA) or their main branches. Other definitions, such as hypertension (HT) and diabetes mellitus, were based on the basis of international guidelines or medication management.

Baseline and outcome data for individual patients were pooled. Continuous variables are expressed as mean \pm standard deviation (SD) and were compared using Student's T-test. Categorical variables are presented as frequencies and proportions and comparisons were performed using the chi-square test or Fisher's exact text, as appropriate.

The rate of cumulative events and incidence curves for clinical outcome were estimated using the Kaplan-Meier method. A Cox proportional hazard regression was performed to determine independent predictors of MACCE, MI, stroke, death and repeat revascularization in univariate and multivariate analyses. The analyses were used to determine the noninferiority of $\mathrm{PCl}$ and to find the adjusted hazards. Adjusted covariates included operation strategy(PCl/CABG), age, sex (male/female), smoking (yes/no), alcohol (yes/no), body mass index (BMI), HT (yes/no), DM (yes/no), hypercholesterolemia (HC, yes/no), family history (yes/no), creatinine clearance rate (CCR), uric acid (UA), C-reactive protein (CRP), blood group (A,B,AB, O), left ventricular ejection fraction (LVEF), prior MI (yes/no), prior heart failure (HF, yes/no), prior stoke (yes/no), prior stent (yes/no), collateral circulation (yes/no), lesion type (LM or three-vessel disease) and Gensini score. Multivariable predictors of outcomes were identified using forward stepwise selection with a significance level of $<0.05$ for entry and exit criteria. Finally, the significant factors and several clinically important factors entered subsequent analysis. The results are reported as hazard ratio $(\mathrm{HR})$ and $95 \%$ confidence interval $(\mathrm{Cl})$.

To reduce selection bias and any other related potential confounding factors, we performed a baseline characteristic adjustment for patients using propensity score. The propensity scores were estimated using a multiple logistic regression model. A full nonparsimonious model was developed that included all variables listed in Tables 1 and 2. Patients who underwent $\mathrm{PCl}$ and patients who underwent $\mathrm{CABG}$ were then matched at a 1:1 ratio by propensity score using a nearest-neighbor matching algorithm with a caliper of 0.01 . The absolute standardized differences of variables included in the calculation of 
propensity score were compared before and after propensity-score matching. Standardized differences $<10 \%$ for these included variables indicated a relatively better balance. The baseline characteristics and outcomes between the two propensity-score-matched subsets were recompared.

Subgroup analyses, including sex, HT, DM, prior MI, prior HF, lesion type and Gensini score, were run using the Cox proportional hazard model. The variables included in the model were significant and were proved in the model design or were clinically relevant. Texts for interaction were performed to assess the heterogeneity of the treatment effect among subgroups. In addition, we utilize the Cox proportional hazard regression to explore the effects of intravascular ultrasound (IVUS) / optical coherence tomography (OCT) and kissing balloon on MACCE that suffered from LM disease and subsequent PCI.

A two-side $p$ value of less than 0.05 was considered to indicate statistical significance. All statistical analyses were carried out using SPSS software version 20.0 (IBM Corporation) or Stata version 14.0 (StataCorp, College Station, TX, USA).

\section{Results}

Between January 2015 and December 2016, a total of 1964 patients underwent angiography and $\mathrm{PCl}$ or CABG in our hospital. However, 1751 patients were removed from our trial by the inclusion and exclusion criteria, leaving 213 patients who entered the study, including $81 \mathrm{CABG}$ and $132 \mathrm{PCl}$ with 2nd DESs (Figure 1).

Baseline demographic characteristics are listed in Table 1. In the overall population, the incidence of smoking $(72.7 \%$ vs. $56.8 \%, p=0.017)$, hyperlipidemia ( $22 \%$ vs. $8.6 \%, p=0.012)$, and several physical and biochemical indexes such as BMI $(28.05 \pm 3.75$ vs. $26.80 \pm 3.18, p=0.013)$, CCR $(130.00 \pm 32.08$ vs.

$121.34 \pm 27.41, p=0.045)$, and $\cup A(390.03 \pm 90.05$ vs. $347.56 \pm 97.86, p=0.001)$ were higher in patients in the $\mathrm{PCl}$ group, whereas the Gensini score $(69.80 \pm 35.10$ vs. $86.64 \pm 36.77, \mathrm{P}=0.001)$ showed the opposite difference. The antiplatelet drug $\mathrm{P}_{2} \mathrm{Y}_{12}$ inhibitor ( $99.2 \%$ vs. $\left.91.4 \%, \mathrm{p}=0.005\right)$ was significantly more common in patients in the $\mathrm{PCl}$ group compared with those in the CABG group. There were no differences between treatment groups in terms of age, sex, HT, DM, LVEF, prior MI, prior HF, lesion type or other factors.

The median duration of follow-up among all patients was 38 months (interquartile range: 36 to 41 months). The cumulative incidences of clinical outcomes of all patients are described in Table 2 (see Additional file 1) and Figure 2. Between the follow-ups, the incidence of MACCE was $20.5 \%$ in the PCl group and $8.6 \%$ in the CABG group (unadjusted HR: 2.508, 95\% Cl: 1.091 to $5.762, \mathrm{p}=0.03$; adjusted HR: $3.263,95 \% \mathrm{Cl}: 1.379$ to $7.722, \mathrm{p}=0.007)$. The incidence of repeat revascularization was $18.9 \%$ in the $\mathrm{PCl}$ group and $3.7 \%$ in the CABG group (unadjusted HR: $5.435,95 \% \mathrm{Cl}: 1.64$ to $18.011, p=0.006$; adjusted HR: $6.968,95 \% \mathrm{Cl}: 2.036$ to $23.842, \mathrm{p}=0.002$ ). There were no significant differences in other endpoints, such as $\mathrm{Ml}$, stoke or death, before or after adjusting for multiple variables and clinical background $(1.5 \% \mathrm{vs}$. $2.5 \%, p=0.86 ; 0$ vs. $2.5 \%, p=0.881 ; 0$ vs. $2.5 \%, p=0.939$, after adjustment, respectively). 
After propensity-score matching was performed, there were 46 matched pairs of patients in the two groups. The baseline characteristics of patients after propensity-score matching are described in Table 3 , and no significant differences were found between the two groups with more variables showing standardized differences less than $10 \%$ that an additional figure file shows this in more detail (see Additional file 2). Compared with the CABG group, the PCl group had a higher prevalence of MACCE ( $32.6 \%$ vs. $10.9 \%$, HR: $4.496,95 \% \mathrm{Cl}: 1.592$ to $12.695, \mathrm{p}=0.005)$ and repeat revascularization $(30.4 \%$ vs. $4.3 \%$, HR: $11.6,95 \% \mathrm{Cl}: 2.449$ to $55.51, \mathrm{p}=0.002$ ) after adjustment. However, as in the overall population, there were no significant differences in the incidence of $\mathrm{MI}(2.2 \%$ vs. $2.2 \%, \mathrm{p}=0.55)$, stoke ( 0 vs. $4.3 \%$, $\mathrm{p}=0.658$ ) or death (0 vs. $2.2 \%, \mathrm{p}=0.876$ ) (Table 4 , Figure 3 ).

Subgroup analyses were performed based on important baseline characteristics. There were no significant interactions between any treatment effects of $\mathrm{PCl}$ versus CABG in the rate of MACCE except for the prior $\mathrm{MI}(\mathrm{p}$ for interaction=0.031). PCl was associated with an increased risk of MACCE in other subgroups. However, the patients who had ever suffered Ml experienced a lower rate of MACCE in the PCI group than in the CABG group (HR: $0.652,95 \% \mathrm{Cl}: 0.125$ to 3.397 ) (Figure 4). In twenty-six LM disease patients who suffered from PCl, there were only six conducted IVUS / OCT and seven performed kissing balloon with no significant difference in MACCE (16.7\% vs. $25 \%$, HR: $1.607,95 \%$ Cl: 0.188 to 13.672 , $\mathrm{p}=0.665 ; 14.3 \%$ vs. $26.3 \%$, HR: $0.498,95 \%$ Cl: 0.058 to $4.267, p=0.525$, respectively).

In the multivariate Cox regression analysis, age (HR: $1.147,95 \%$ Cl: 1.004 to $1.312, p=0.044)$, CRP (HR: 1.011, 95\% Cl: 1.005 to $1.016, p=0.00)$, Gensini score (HR: 1.013, 95\% Cl: 1.004 to $1.022, p=0.006$ ) and operation strategy (HR: $3.263,95 \% \mathrm{Cl}: 1.379$ to $7.722, p=0.007$ ) were found to be predictors of MACCE.

Predictors of repeat revascularization were CRP (HR: 1.011, 95\% Cl: 1.005 to $1.016, p=0.00)$, Gensini score (HR: $1.012,95 \% \mathrm{Cl}: 1.002$ to $1.022, p=0.018$ ) and operation strategy (HR: 6.968, 95\% Cl: 2.036 to 23.842, $p=0.002$ ). There were no significant predictors of other endpoints.

\section{Discussion}

In this retrospective study, CABG was shown to be superior to PCl with 2nd-generation DESs in young patients with LM and/or three-vessel disease in terms of the incidence of MACCE, which was driven mainly by repeat revascularization. There were no significant differences the hard endpoints death, MI and stoke in line with the outcomes of the recent EXCLE trial (8). After adjustment by propensity-score matching to minimize selection bias, the conclusion was the same as in the overall population. Although this study was limited by its observational design, this is the first report specifically addressing the issue of $L M$ and three-vessel disease in young patients, and it evaluated the potential noninferiority of $\mathrm{PCl}$ over CABG. Therefore, our results would be helpful when making a clinical decision in real-world practice, especially for young CAD patients.

It is a good thing that young patients have better baseline characteristics along with fewer and milder complications, so it is essential to consider the broad indications and long-term prognosis. In our study, there were no obvious differences between the two groups in baseline characteristics, except the CABG 
group had more complex coronary anatomy and lower usage of dual antiplatelets. However, the PCl group showed a higher incidence of MACCE and repeat revascularization.

As in some previous studies, we found that CABG was better than $\mathrm{PCl}$ for the composite endpoint of MACCE and repeat revascularization both in $\operatorname{LM}(6)$ and three-vessel disease $(3,12,15)$. One of the reasons is that after $\mathrm{PCl}$, progressive atherosclerosis can lead to new, severe stenosis and plaque rupture that may cause ischemia and repeat revascularization, and CABG offers better protection by bypassing a large proportion of obstructive lesions or vulnerable plaques, minimizing the impact of progressive disease in the entire upstream proximal vessel (16). Moreover, there was more incomplete revascularization in the $\mathrm{PCl}$ group that needed more than one intervention operation, whereas patients achieving complete revascularization showed similar outcomes between PCl and CABG (17). In addition, more routine angiographic follow-up was performed to detect early in-stent restenosis in patients treated with $\mathrm{PCl}$ rather than those with $\mathrm{CABG}$. Many patients with $\mathrm{PCl}$ receive repeat revascularization that is angiographically rather than clinically driven. Thus, the rate of repeat revascularization might be underestimated for those patients undergoing CABG. We must recognize that with the introduction of high-pressure deployment, use of intravascular ultrasound, and improved stent design, restenosis of drugeluting stent has diminished over time $(10,18)$.

Some studies proved that the $\mathrm{PCl}$ group had higher rates of $\mathrm{MI}(19,20)$, whereas other studies $(21,22)$ supported our finding that there were similar rates of $\mathrm{MI}$ between the $\mathrm{PCl}$ and $\mathrm{CABG}$ groups. The main advantage of CABG might be the bypassing of long lesion segments by grafting, which protects, to a great extent, against target lesion $\mathrm{MI}$ and proximal de- novo lesion $\mathrm{MI}(10,11)$. The small population and short follow-up time may be two of the reasons that caused the absence of significant differences in $\mathrm{MI}$ rates.

While some other studies showed that CABG resulted in significantly higher rates of stoke compared with $\mathrm{PCl}$ for $\mathrm{LM}$ or multivessel disease $(5,23)$, we found that the difference in rates was indistinctive. The mechanisms underlying the increased risk of stoke with CABG are likely multifactorial. First, CABG performed on-pump with cannulation and clamping of the aorta increases the rates of stoke, which may be reduced by an off-pump procedure (24). Furthermore, stoke may be less common after PCl due to the routine use of dual antiplatelets after stent implantation. However, in the present study, the CABG group also had higher usage of aspirin and clopidogrel or ticagrelor.

Partly different from Head's study (25), we and Park et al. shared the same outcome in terms of death to a certain extent (4), i.e., that there was no significant difference in the rate of death between the $\mathrm{PCl}$ and CABG groups. The low mortality after treatment in both groups showed that modern revascularization techniques and adjunctive therapy can lead to excellent survival in young patients with LM and threevessel disease. All these low incidences of $\mathrm{MI}$, stoke and death might relate to the young characteristics of the patients enrolled in our study.

In the subgroup analysis, we found that CABG might lead to higher rates of MACCE in patients who had previously suffered $\mathrm{MI}$, whereas in the opposite patients, $\mathrm{PCl}$ caused more MACCE. No relevant studies 
support this discovery, so it will be important to conduct further studies to see if this finding is generalizable.

In contrast to previous reports involving multivessel or LM disease in part, we found that, along with operation strategy, the predictors of MACCE and repeat revascularization were age, CRP and Gensini score. It is possible that, the inflammation condition and coronary anatomy play an important role in the long-term curative effect, which has been verified by other studies. Kosmoidou et al. (26)found that elevated baseline CRP level was strongly associated with subsequent death, MI and stoke. Misumida et al. (27) detected that SYNTAX score 2 was correlated with mortality. However, some predictors such as diabetes mellitus (28), heart failure (29), chronic renal failure (30) and so on, which proved related to MACCE in other studies, were not included in our finding. From a clinical viewpoint, using these relevant variables that were considered potential predictors of MACCE in young patients with LM and three-vessel disease, represents a first step to implementing further preventive measures and tailored therapies.

Considering the discussion above, patients in the PCl group with a 2nd DES had higher rates of repeat revascularization, which did not translate into a higher incidence of the hard endpoints of $\mathrm{Ml}$, stoke and death. A recent meta-analysis and the PRECOMBAT study also supports our results $(6,31)$. The young age of our patients could explain this result, but it is important to select appropriate operations for longterm survival. The relative benefits of CABG versus PCl with stents in terms of outcomes are highly debated, particularly with each advancement in stent design. Now, the state-of-the art stent is the secondgeneration DES, which is thinner and is coated with a more biocompatible polymer and new 'limus' drugs that allow less inflammation and a lower rate of restenosis compared with first-generation $\operatorname{DESs}(12,32$, 33). What's more, with the development of technology, some technique such as IVUS, OCT and kissing balloon may improve prognosis. The kissing balloon can reduce the risk of overall target lesion revascularization while the IVUS and OCT can be used to optimize stenting and guide procedural strategy $(34,35)$. PCl may also be preferred because of its improved early safety profile.

The internal mammary arteries have been widely used as conduits to the left anterior descending artery due to their long-term patency, and the advantage of CABG may be partially due to the completeness of revascularization (36). Although high long-term patency of the internal mammary artery is expected, some vein graft degeneration can be expected beyond 5 years (10). Multiple arterial grafting is associated with improved survival and a reduced requirement of reintervention compared with grafting of a single internal thoracic artery plus the saphenous vein (37). In the current era, routine use of the right internal mammary artery has not been widely adopted despite its identical histological features to the left internal mammary artery due to technical difficulties and concerns about a potential increase in rates of bleeding and wound complication(20).

Saphenous vein grafts are routinely used in CABG surgery as additional conduits to artery grafts. However, saphenous vein grafts typically present accelerated atherosclerosis resulting in a high rate of stenosis or occlusion of the graft, which contributes to higher morbidity and mortality (38). In the case of graft failure, repeat revascularization after either $\mathrm{PCl}$ or $\mathrm{CABG}$ is necessary in a certain number of 
patients, if appropriate. Nevertheless, in addition to an increased operation difficulty, patients undergoing re-CABG have a 2- to 4-fold higher mortality than they do in the first operation, whereas $\mathrm{PCl}$ in patients previously treated with $C A B G$ is associated with worse acute and long-term outcomes compared with native artery $\mathrm{PCl}(39,40)$.

Our study had some limitations. First, it was a nonrandomized, retrospective study, although we performed propensity-score matching to minimize the potential selection bias and ascertainment bias. Second, the follow-up duration and number of enrolled patients might not be sufficient to evaluate the long-term outcomes of revascularization. Third, this was a single-center study that only included Chinese, and more ethnicities are required in further trials. Fourth, because the treatment choice was left to the physician or patients, selection bias was inevitable. Moreover, some patients who underwent CABG, had the angiography done in outside hospitals rather than our hospital, which affected our evaluation of the lesion. Finally, we used the prevalent SYNTAX score with the Gensini score to estimate the anatomic complexity due to practical considerations.

\section{Conclusion}

In our retrospective study evaluating $\mathrm{PCl}$ with second $\mathrm{DES}$ s versus $\mathrm{CABG}$ in young patients with $\mathrm{LM}$ and/or three-vessel disease in the real world, the PCI group suffered higher rates of MACCE compared with the CABG group, which was driven by repeat revascularization, but did not translate into a higher incidence of hard endpoints, such as Ml, stoke and death. In our opinion, for these young patients, along with the technical development of second-generation DESs for PCl, higher use of IVUS and fractional flow reserve and new imaging techniques, such as $\mathrm{OCT}$, may be an alternative treatment strategy to CABG for long-term prognosis. Of course, further research and longer follow-up durations are indispensable.

\section{Abbreviation}

BMI: body mass index; $C A B G$ : coronary artery bypass grafting; CAD: coronary artery disease; PCl: percutaneous coronary intervention; DES: drug eluting stent; CCR: creatinine clearance rate; UA: uric acid; LVEF: left ventricular ejection fraction; HF: heart failure; MI: myocardial infarction; CRP: C-reactive protein; MACCE: major adverse cardiovascular or cerebrovascular events which are the composite of all-cause death, stroke, $\mathrm{Ml}$, and ischemia-driven revascularization; $\mathrm{HT}$ : hypertension; DM: diabetes mellitus; LM disease: left main coronary artery disease, which includes LM coronary artery disease in isolation and LM coronary artery disease with multivessel disease (three-vessel disease); IVUS: intravascular ultrasound; OCT: optical coherence tomography.

\section{Declarations}

\section{Ethics approval and consent to participate}


The ethics committee at our hospital (Beijing Anzhen Hospital) reviewed our study protocol and approved the use of clinical data for the study (No: 2018020X). Because of the retrospective nature of our trial, the need for patient informed consent was waived.

\section{Consent for publication}

Not applicable.

\section{Availability of data and materials}

The datasets used and analyzed during the current study are available from the corresponding author on reasonable request.

\section{Competing interests}

The authors declare that they have no competing interests.

\section{Funding}

This study is supported by the National Natural Science Foundation of China (81370437 and 81870368 ). The funding bodies assisted in service charge and publication fees. There were no roles of the funding bodies in the design of the study and collection, analysis, and interpretation of data and in writing the manuscript.

\section{Authors' contributions}

$X C, X Z, Y Y, X Z, M N, T F, Z L$ and $Q Z$ designed the study. $X C, X Z$ and $Y Y$ contributed the data collection. $X C$, $Y Y$ and $X Z$ did the data analysis. $X C$ and $M N$ constructed to the tables and figures. $X C, T F, Z L$ and $Q Z$ interpreted the data. $\mathrm{XC}$ wrote the first draft of the manuscript. All authors critically reviewed the manuscript and approved the final version and its submission.

\section{Acknowledgements}

Not applicable.

\section{Authors' information}

1 Beijing Anzhen Hospital, Affiliated to Capital Medical University, Beijing Institute of Heart, Lung and Blood Vessel Diseases. The Key Laboratory of Remodelling-related Cardiovascular Diseases, Department of Cardiology, 2 Anzhen Road, Chaoyang District, Beijing 100029, China.

\section{References}


1. Modolo R, Chichareon P, Kogame N, Dressler O, Crowley A, Ben-Yehuda O, et al. Contemporary Outcomes Following Coronary Artery Bypass Graft Surgery for Left Main Disease. J Am Coll Cardiol. 2019;73(15):1877-86.

2. Milojevic M, Serruys PW, Sabik JF, 3rd, Kandzari DE, Schampaert E, van Boven AJ, et al. Bypass Surgery or Stenting for Left Main Coronary Artery Disease in Patients With Diabetes. J Am Coll Cardiol. 2019;73(13):1616-28.

3. Mohr FW, Morice M-C, Kappetein AP, Feldman TE, Ståhle E, Colombo A, et al. Coronary artery bypass graft surgery versus percutaneous coronary intervention in patients with three-vessel disease and left main coronary disease: 5-year follow-up of the randomised, clinical SYNTAX trial. The Lancet. 2013;381(9867):629-38.

4. Park DW, Ahn JM, Yun SC, Yoon YH, Kang DY, Lee PH, et al. 10-Year Outcomes of Stents Versus Coronary Artery Bypass Grafting for Left Main Coronary Artery Disease. J Am Coll Cardiol. 2018;72(23 Pt A):2813-22.

5. Head SJ, Milojevic M, Daemen J, Ahn JM, Boersma E, Christiansen EH, et al. Stroke Rates Following Surgical Versus Percutaneous Coronary Revascularization. J Am Coll Cardiol. 2018;72(4):386-98.

6. Ahn JM, Roh JH, Kim YH, Park DW, Yun SC, Lee PH, et al. Randomized Trial of Stents Versus Bypass Surgery for Left Main Coronary Artery Disease: 5-Year Outcomes of the PRECOMBAT Study. J Am Coll Cardiol. 2015;65(20):2198-206.

7. Neumann FJ, Sousa-Uva M, Ahlsson A, Alfonso F, Banning AP, Benedetto U, et al. 2018 ESC/EACTS Guidelines on myocardial revascularization. Eur Heart J. 2019;40(2):87-165.

8. Stone GW, Sabik JF, Serruys PW, Simonton CA, Genereux P, Puskas J, et al. Everolimus-Eluting Stents or Bypass Surgery for Left Main Coronary Artery Disease. The New England journal of medicine. 2016;375(23):2223-35.

9. Kukreja N, Serruys PW, De Bruyne B, Colombo A, Macaya C, Richardt G, et al. Sirolimus-eluting stents, bare metal stents or coronary artery bypass grafting for patients with multivessel disease including involvement of the proximal left anterior descending artery: analysis of the Arterial Revascularization Therapies study part 2 (ARTS-II). Heart. 2009;95(13):1061-6.

10. Mäkikallio T, Holm NR, Lindsay M, Spence MS, Erglis A, Menown IBA, et al. Percutaneous coronary angioplasty versus coronary artery bypass grafting in treatment of unprotected left main stenosis (NOBLE): a prospective, randomised, open-label, non-inferiority trial. The Lancet. 2016;388(10061):2743-52.

11. Milojevic M, Head SJ, Parasca CA, Serruys PW, Mohr FW, Morice MC, et al. Causes of Death Following PCI Versus CABG in Complex CAD: 5-Year Follow-Up of SYNTAX. J Am Coll Cardiol. 2016;67(1):42-55.

12. Tsuneyoshi H, Komiya T, Kadota K, Shimamoto T, Sakai J, Hiraoka T, et al. Coronary artery bypass surgery is superior to second generation drug-eluting stents in three-vessel coronary artery disease: a propensity score matched analysis. Eur J Cardiothorac Surg. 2017;52(3):462-8. 
13. Sabik JF, 3rd, Blackstone EH, Gillinov AM, Smedira NG, Lytle BW. Occurrence and risk factors for reintervention after coronary artery bypass grafting. Circulation. 2006;114(1 Suppl):I454-60.

14. Head SJ, Davierwala PM, Serruys PW, Redwood SR, Colombo A, Mack MJ, et al. Coronary artery bypass grafting vs. percutaneous coronary intervention for patients with three-vessel disease: final five-year follow-up of the SYNTAX trial. Eur Heart J. 2014;35(40):2821-30.

15. Park SJ, Ahn JM, Kim YH, Park DW, Yun SC, Lee JY, et al. Trial of everolimus-eluting stents or bypass surgery for coronary disease. The New England journal of medicine. 2015;372(13):1204-12.

16. Cui K, Lyu S, Song X, Liu H, Yuan F, Xu F, et al. Drug-Eluting Stent Versus Coronary Artery Bypass Grafting for Diabetic Patients With Multivessel and/or Left Main Coronary Artery Disease: A MetaAnalysis. Angiology. 2019:3319719839885.

17. Ahn JM, Park DW, Lee CW, Chang M, Cavalcante R, Sotomi Y, et al. Comparison of Stenting Versus Bypass Surgery According to the Completeness of Revascularization in Severe Coronary Artery Disease: Patient-Level Pooled Analysis of the SYNTAX, PRECOMBAT, and BEST Trials. JACC Cardiovasc Interv. 2017;10(14):1415-24.

18. Park SJ, Kim YH, Park DW, Lee SW, Kim WJ, Suh J, et al. Impact of intravascular ultrasound guidance on long-term mortality in stenting for unprotected left main coronary artery stenosis. Circ Cardiovasc Interv. 2009;2(3):167-77.

19. Lee CW, Ahn JM, Cavalcante R, Sotomi Y, Onuma Y, Suwannasom P, et al. Coronary Artery Bypass Surgery Versus Drug-Eluting Stent Implantation for Left Main or Multivessel Coronary Artery Disease: A Meta-Analysis of Individual Patient Data. JACC Cardiovasc Interv. 2016;9(24):2481-9.

20. Jeong DS, Lee YT, Chung SR, Jeong JH, Kim WS, Sung K, et al. Revascularization in left main coronary artery disease: comparison of off-pump coronary artery bypass grafting vs percutaneous coronary intervention. Eur J Cardiothorac Surg. 2013;44(4):718-24.

21. Chieffo A, Meliga E, Latib A, Park SJ, Onuma Y, Capranzano P, et al. Drug-eluting stent for left main coronary artery disease. The DELTA registry: a multicenter registry evaluating percutaneous coronary intervention versus coronary artery bypass grafting for left main treatment. JACC Cardiovasc Interv. 2012;5(7):718-27.

22. Putzu A, Gallo M, Martino EA, Ferrari E, Pedrazzini G, Moccetti T, et al. Coronary artery bypass graft surgery versus percutaneous coronary intervention with drug-eluting stents for left main coronary artery disease: A meta-analysis of randomized trials. Int J Cardiol. 2017;241:142-8.

23. Palmerini T, Biondi-Zoccai G, Reggiani LB, Sangiorgi D, Alessi L, De Servi S, et al. Risk of stroke with coronary artery bypass graft surgery compared with percutaneous coronary intervention. J Am Coll Cardiol. 2012;60(9):798-805.

24. Head SJ, Borgermann J, Osnabrugge RL, Kieser TM, Falk V, Taggart DP, et al. Coronary artery bypass grafting: Part 2-optimizing outcomes and future prospects. Eur Heart J. 2013;34(37):2873-86.

25. Head SJ, Milojevic M, Daemen J, Ahn J-M, Boersma E, Christiansen EH, et al. Mortality after coronary artery bypass grafting versus percutaneous coronary intervention with stenting for coronary artery disease: a pooled analysis of individual patient data. The Lancet. 2018;391(10124):939-48. 
26. Kosmidou I, Redfors B, Chen S, Crowley A, Lembo NJ, Karmpaliotis D, et al. C-reactive protein and prognosis after percutaneous coronary intervention and bypass graft surgery for left main coronary artery disease: Analysis from the EXCEL trial. Am Heart J. 2019;210:49-57.

27. Misumida N, Ahmed AE, Barlow M, Goodwin R, Goodwin E, Musa A, et al. Prognostic Value of Anatomical SYNTAX Score and SYNTAX Score II in Veterans With Left Main and/or Three-Vessel Coronary Artery Disease. Am J Cardiol. 2018;122(2):213-9.

28. Roffi M, Angiolillo DJ, Kappetein AP. Current concepts on coronary revascularization in diabetic patients. Eur Heart J. 2011;32(22):2748-57.

29. Kang SH, Ahn JM, Lee CH, Lee PH, Kang SJ, Lee SW, et al. Differential Event Rates and Independent Predictors of Long-Term Major Cardiovascular Events and Death in 5795 Patients With Unprotected Left Main Coronary Artery Disease Treated With Stents, Bypass Surgery, or Medication: Insights From a Large International Multicenter Registry. Circ Cardiovasc Interv. 2017;10(7).

30. Cooper WA, O'Brien SM, Thourani VH, Guyton RA, Bridges CR, Szczech LA, et al. Impact of renal dysfunction on outcomes of coronary artery bypass surgery: results from the Society of Thoracic Surgeons National Adult Cardiac Database. Circulation. 2006;113(8):1063-70.

31. Shah R, Morsy MS, Weiman DS, Vetrovec GW. Meta-Analysis Comparing Coronary Artery Bypass Grafting to Drug-Eluting Stents and to Medical Therapy Alone for Left Main Coronary Artery Disease. Am J Cardiol. 2017;120(1):63-8.

32. Sarno G, Lagerqvist B, Nilsson J, Frobert O, Hambraeus K, Varenhorst C, et al. Stent thrombosis in new-generation drug-eluting stents in patients with STEMI undergoing primary PCl: a report from SCAAR. J Am Coll Cardiol. 2014;64(1):16-24.

33. Deb S, Wijeysundera HC, Ko DT, Tsubota H, Hill S, Fremes SE. Coronary artery bypass graft surgery vs percutaneous interventions in coronary revascularization: a systematic review. JAMA. 2013;310(19):2086-95.

34. D'Ascenzo F, Omede P, De Filippo O, Cerrato E, Autelli M, Trabattoni D, et al. Impact of Final Kissing Balloon and of Imaging on Patients Treated on Unprotected Left Main Coronary Artery With ThinStrut Stents (From the RAIN-CARDIOGROUP VII Study). The American journal of cardiology. 2019;123(10):1610-9.

35. Koskinas KC, Nakamura M, Raber L, Colleran R, Kadota K, Capodanno D, et al. Current use of intracoronary imaging in interventional practice - Results of a European Association of Percutaneous Cardiovascular Interventions (EAPCI) and Japanese Association of Cardiovascular Interventions and Therapeutics (CVIT) Clinical Practice Survey. Eurolntervention. 2018;14(4):e475-e84.

36. Farooq V, Serruys PW, Garcia-Garcia HM, Zhang Y, Bourantas CV, Holmes DR, et al. The negative impact of incomplete angiographic revascularization on clinical outcomes and its association with total occlusions: the SYNTAX (Synergy Between Percutaneous Coronary Intervention with Taxus and Cardiac Surgery) trial. J Am Coll Cardiol. 2013;61(3):282-94.

37. Kieser TM, Lewin AM, Graham MM, Martin BJ, Galbraith PD, Rabi DM, et al. Outcomes associated with bilateral internal thoracic artery grafting: the importance of age. Ann Thorac Surg. 
2011;92(4):1269-75; discussion 75-6.

38. Scarsini R, Zivelonghi C, Pesarini G, Vassanelli C, Ribichini FL. Repeat revascularization:

Percutaneous coronary intervention after coronary artery bypass graft surgery. Cardiovasc Revasc Med. 2016;17(4):272-8.

39. Sabik JF, 3rd, Blackstone EH, Houghtaling PL, Walts PA, Lytle BW. Is reoperation still a risk factor in coronary artery bypass surgery? Ann Thorac Surg. 2005;80(5):1719-27.

40. Tejada JG, Velazquez M, Hernandez F, Albarran A, Gomez I, Rodriguez S, et al. Percutaneous revascularization in patients with previous coronary artery bypass graft surgery. Immediate and 1year clinical outcomes. Int J Cardiol. 2009;134(2):201-6.

\section{Tables}

Table 1: Baseline characteristic of overall patients 


\begin{tabular}{|c|c|c|c|}
\hline & CABG & PCI with 2nd DES & $\mathrm{P}$ value \\
\hline & $\mathrm{n}=81$ & $\mathrm{n}=132$ & \\
\hline Age (year) & $42.15 \pm 2.82$ & $41.67 \pm 3.49$ & 0.295 \\
\hline Male & 73ロ90.1\%ロ & $124 \square 93.9 \% \square$ & 0.305 \\
\hline Smoking (current or former) & $46 \square 56.8 \% \square$ & $96 \square 72.7 \% \square$ & 0.017 \\
\hline Drinking (current or former) & $17(21 \%)$ & $38(28.8 \%)$ & 0.207 \\
\hline Hypertension & $43(53.1 \%)$ & $80 \square 60.6 \% \square$ & 0.281 \\
\hline Diabetes mellitus & $21(25.9 \%)$ & $36(27.3 \%)$ & 0.829 \\
\hline Hyperlipidemia & $7(8.6 \%)$ & $29(22.0 \%)$ & 0.012 \\
\hline BMI $\left(\mathrm{kg} / \mathrm{m}^{2}\right)$ & $26.80 \pm 3.18$ & $28.05 \pm 3.75$ & 0.013 \\
\hline $\mathrm{CCR}(\mathrm{ml} / \mathrm{min})$ & $121 . .34 \pm 27.41$ & $130.00 \pm 32.08$ & 0.045 \\
\hline UA (umol/l) & $347.56 \pm 97.86$ & $390.03 \pm 90.05$ & 0.001 \\
\hline $\mathrm{CRP}(\mathrm{mg} / \mathrm{l})$ & $2.59 \pm 5.44$ & $6.32 \pm 38.02$ & 0.383 \\
\hline Family history & $16(19.8 \%)$ & 39 (29.5\%) & 0.113 \\
\hline \multicolumn{4}{|l|}{ Blood group } \\
\hline & $27(33.3 \%)$ & $43(32.6 \%)$ & 0.962 \\
\hline A & $22(27.2 \%)$ & $37(28.0 \%)$ & \\
\hline B & $9(11.1 \%)$ & $12(9.1 \%)$ & \\
\hline $\mathrm{AB}$ & $23(28.4 \%)$ & $40(30.3 \%)$ & \\
\hline $\begin{array}{c}\mathrm{O} \\
\operatorname{LVEF}(\%)\end{array}$ & $59.95 \pm 8.41$ & $61.83 \pm 7.25$ & 0.085 \\
\hline Prior HF & 17 (21.0\%) & 38 (28.8\%) & 0.207 \\
\hline Prior MI & 14 (17.3\%) & 31 (23.5\%) & 0.282 \\
\hline Prior stoke & $1(1.2 \%)$ & $3(2.3 \%)$ & 0.664 \\
\hline Prior stent & $6(7.4 \%)$ & $16(12.1 \%)$ & 0.272 \\
\hline
\end{tabular}




\begin{tabular}{llll} 
Collateral ciraulation & $3(3.7 \%)$ & $10(7.6 \%)$ & 0.378 \\
Lesion type & & & 0.366 \\
LM with/without three-vessel disease & $12(14.8 \%)$ & $26(19.7 \%)$ & \\
Three-vessel disease isolated & $69(85.2 \%)$ & $106(80.3 \%)$ & \\
Gensini score & $86.64 \pm 36.77$ & $69.80 \pm 35.10$ & 0.001 \\
$<60$ & $25(30.9 \%)$ & $62(47.0 \%)$ & \\
$\geq 60$ & $56(69.1 \%)$ & $70(53.0 \%)$ & \\
Discharge medication & & & 1.00 \\
Aspirin & $80(98.8 \%)$ & $131(99.2 \%)$ & 0.005 \\
$\mathrm{P}_{2} \mathrm{Y}_{12}$ inhibitor & $74(91.4 \%)$ & $131(99.2 \%)$ & 0.016 \\
Dual antiplatelet & $74(91.4 \%)$ & $130(98.5 \%)$ & 0.30 \\
Statin & $78(96.3 \%)$ & $131(99.2 \%)$ & 0.457 \\
Beta blocker & $70(86.4 \%)$ & $109(82.6 \%)$ & \\
\hline
\end{tabular}

BMI: Body mass index; CABG: coronary artery bypass grafting; CCR: creatinine clearance rate; CRP: C-reactive protein; DES: drug eluting stent; HF: heart failure; LM: left main; LVEF: left ventricular ejection fraction; MI: myocardial infarction; PCI: percutaneous coronary intervention; UA: uric acid

Data are expressed as mean $\pm \mathrm{SD}$. Bold number: $\mathrm{P}<0.05$

HD: hemodialysis; BMI: body mass index; BP: systolic blood pressure; DBP: diastolic blood pressure; CREA: serum creatinine; ESRD: end-stage renal disease.

Table 2. Comparison of traditional echocardiographic parameters between control and MHD groups 


\begin{tabular}{cccc}
\hline & MHD & Normal & P-value \\
\hline LVIDD (mm) & $52.56 \pm 6.13$ & $46.06 \pm 3.07$ & $<0.001$ \\
LVIDS (mm) & $36.65 \pm 5.55$ & $31.11 \pm 2.84$ & $<0.001$ \\
IVST (mm) & $11.56 \pm 1.62$ & $8.86 \pm 1.38$ & $<0.001$ \\
LVPWT (mm) & $11.24 \pm 1.50$ & $8.14 \pm 1.38$ & $<0.001$ \\
LAD (mm) & $42.38 \pm 5.29$ & $34.86 \pm 3.12$ & $<0.001$ \\
LVEF (\%) & $58.24 \pm 5.16$ & $60.11 \pm 4.00$ & 0.095 \\
LVMI (g/m $)$ & $56.59 \pm 9.11$ & $31.60 \pm 3.82$ & $<0.001$ \\
E/A & $0.99 \pm 0.15$ & $1.15 \pm 0.19$ & $<0.001$ \\
E/e' & $7.97 \pm 1.67$ & $7.08 \pm 1.36$ & 0.019 \\
\hline
\end{tabular}

Table 3: Baseline characteristic of the patients after adjusted by propensity-score matching 


\begin{tabular}{|c|c|c|c|}
\hline & $\begin{array}{l}\text { CABG } \\
\mathrm{n}=46\end{array}$ & $\begin{array}{l}\text { PCI with 2nd DES } \\
n=46\end{array}$ & $\mathrm{P}$ value \\
\hline Age (year) & $42.04 \pm 3.00$ & $42.02 \pm 2.56$ & 0.970 \\
\hline Male & $42 \square 91.3 \% \square$ & 43ロ93.5\%ロ & 0.694 \\
\hline Smoking (current or former) & $29(63.0 \%)$ & $28(60.9 \%)$ & 0.830 \\
\hline Drinking (current or former) & $13(28.3 \%)$ & $12(26.1 \%)$ & 0.815 \\
\hline Hypertension & $23(50.0 \%)$ & $26(56.5 \%)$ & 0.531 \\
\hline Diabetes mellitus & $12(26.1 \%)$ & $10(21.7 \%)$ & 0.625 \\
\hline Hyperlipidemia & $5(10.9 \%)$ & $6(13.0 \%)$ & 0.748 \\
\hline BMI $\left(\mathrm{kg} / \mathrm{m}^{2}\right)$ & $27.46 \pm 3.23$ & $27.58 \pm 3.56$ & 0.873 \\
\hline $\mathrm{CCR}(\mathrm{ml} / \mathrm{min})$ & $122 . .34 \pm 27.49$ & $122.77 \pm 33.58$ & 0.947 \\
\hline UA (umol/l) & $381.33 \pm 82.28$ & $385.45 \pm 84.74$ & 0.813 \\
\hline $\mathrm{CRP}(\mathrm{mg} / \mathrm{l})$ & $2.59 \pm 5.44$ & $6.32 \pm 38.02$ & 0.935 \\
\hline Family history & $10(21.7 \%)$ & $12(26.1 \%)$ & 0.625 \\
\hline \multicolumn{4}{|l|}{ Blood group } \\
\hline & $17(37.0 \%)$ & $16(34.8 \%)$ & 0.850 \\
\hline A & $13(28.3 \%)$ & $13(28.3 \%)$ & \\
\hline B & $6(13.0 \%)$ & $4(8.7 \%)$ & \\
\hline $\mathrm{AB}$ & $10(21.7 \%)$ & $13(28.3 \%)$ & \\
\hline$\stackrel{\mathrm{O}}{\operatorname{LVEF}(\%)}$ & $61.59 \pm 8.00$ & $59.72 \pm 7.70$ & 0.256 \\
\hline Prior HF & $8(17.4 \%)$ & 10 (21.7\%) & 0.599 \\
\hline Prior MI & $10(21.7 \%)$ & $11(23.9 \%)$ & 0.804 \\
\hline Prior stoke & $1(2.2 \%)$ & $1(2.2 \%)$ & 1.000 \\
\hline Prior stent & $4(8.7 \%)$ & $1(2.2 \%)$ & 0.361 \\
\hline
\end{tabular}




\begin{tabular}{llll} 
Collateral ciraulation & $3(6.5 \%)$ & $4(8.7 \%)$ & 0.694 \\
Lesion type & & & 0.562 \\
LM with/without three-vessel disease & $8(17.4 \%)$ & $4(13.0 \%)$ & \\
Three-vessel disease isolated & $38(82.6 \%)$ & $40(87.0 \%)$ & \\
Gensini score & $74.85 \pm 28.06$ & $78.75 \pm 38.66$ & 0.581 \\
$<60$ & $19(41.30 \%)$ & $17(37.0 \%)$ & \\
$\geq 60$ & $27(58.70 \%)$ & $29(63.0 \%)$ & \\
Discharge medication & & & 1.00 \\
Aspirin & $46(100 \%)$ & $46(100 \%)$ & 0.495 \\
$\mathrm{P}_{2} \mathrm{Y}_{12}$ inhibitor & $44(95.7 \%)$ & $46(100 \%)$ & 0.495 \\
Dual antiplatelet & $44(95.7 \%)$ & $46(100 \%)$ & 1.000 \\
Statin & $46(100 \%)$ & $45(97.8 \%)$ & 0.522 \\
Beta blocker & $39(84.8 \%)$ & $42(91.3 \%)$ & \\
\hline
\end{tabular}

BMI: body mass index; CABG: coronary artery bypass grafting; CCR: creatinine clearance rate; CRP: C-reactive protein; DES: drug eluting stent; HF: heart failure; LM: left main; LVEF: left ventricular ejection fraction; MI: myocardial infarction; PCI: percutaneous coronary intervention; UA: uric acid

Table 4: Clinical outcome after adjusted by propensity-score match 


\begin{tabular}{lcccc}
\hline & $\begin{array}{c}\text { PCI } \\
(\mathrm{n}=46)\end{array}$ & $\begin{array}{c}\text { CABG } \\
(\mathrm{n}=46)\end{array}$ & $\begin{array}{c}\text { HR } \\
(95 \% \mathrm{CI})\end{array}$ & P value \\
\hline MACCE & $15(32.6 \%)$ & $5(10.9 \%)$ & 4.496 & 0.005 \\
MI & $1(2.2 \%)$ & $1(2.2 \%)$ & $\begin{array}{c}(1.592,12.695) \\
2635462740\end{array}$ & 0.550 \\
Stoke & 0 & $2(4.3 \%)$ & $(0.00,2.092 \mathrm{E}+040)$ & 0 \\
Death & 0 & $1(2.2 \%)$ & $(0.00,5.141 \mathrm{E}+16)$ & 0.658 \\
Repeat & & & 0.001 & 0.876 \\
revascularization & $14(30.4 \%)$ & $2(4.3 \%)$ & $(0.00,1.299 \mathrm{E}+036)$ & 0.002 \\
\end{tabular}

CABG: coronary artery bypass grafting; CI: confidence interval; HR: hazard ratio; MACCE: major adverse cardiovascular or cerebrovascular events which is the composite of allcause death, stroke, MI, or repeat revascularization; MI: myocardial infarction; PCI: percutaneous coronary intervention.

\section{Additional Files}

Additional file 1.xls: Table 2: Clinical outcome of overall patients before adjusted by propensity-score matching.

CABG: coronary artery bypass grafting; Cl: confidence interval; HR: hazard ratio; MACCE: major adverse cardiovascular or cerebrovascular events which is the composite of all-cause death, stroke, $\mathrm{Ml}$, or repeat revascularization; MI: myocardial infarction; PCl: percutaneous coronary intervention.

Additional file 2.tif: Standardized differences before and after propensity-score matching. An absolute standardized difference of less than $10 \%$ indicates a good match. Abbreviations as in Table 1.

\section{Figures}




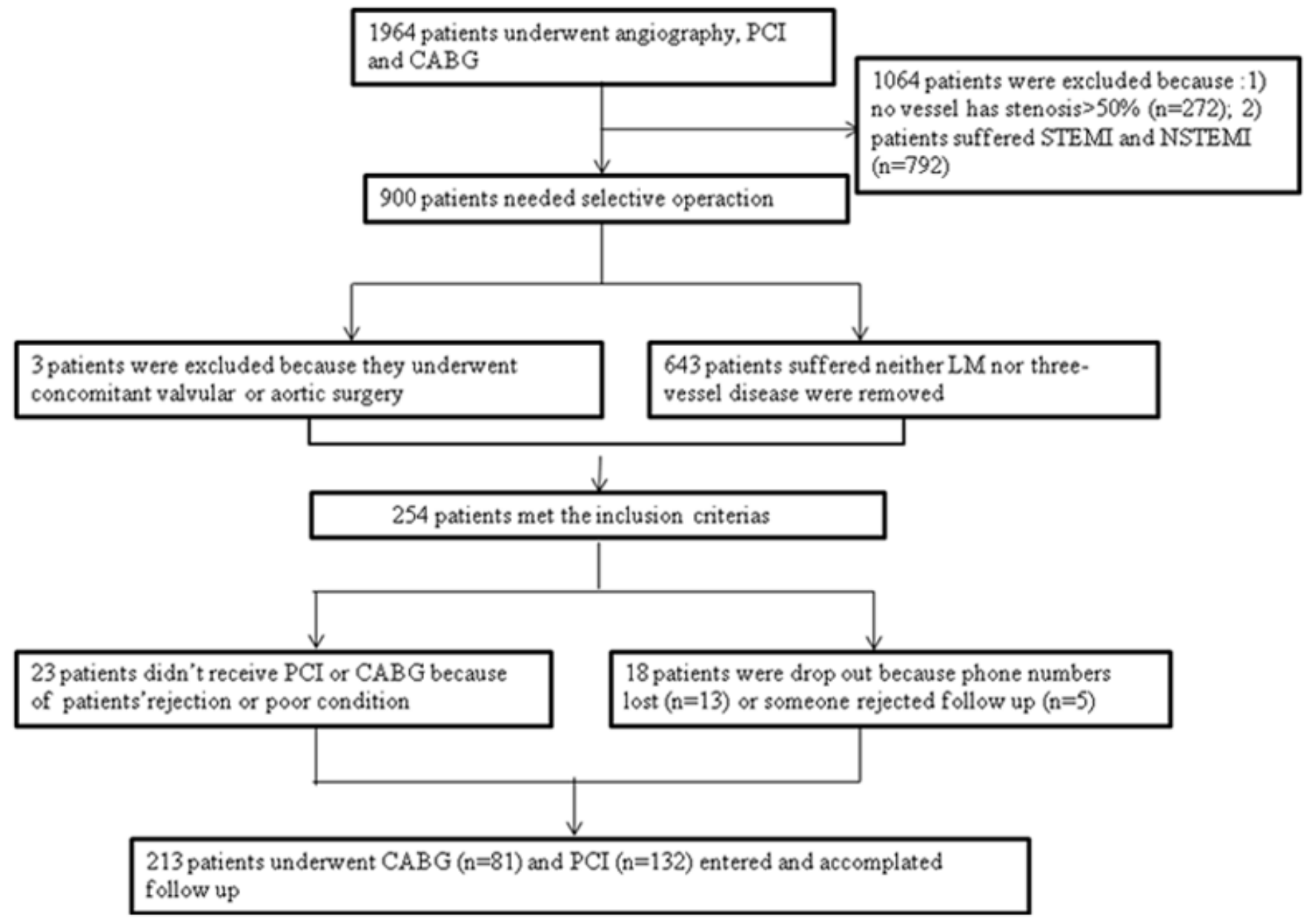

\section{Figure 1}

Flow chart of enrolled patients PCl: percutaneous coronary intervention; CABG: coronary artery bypass grafting; STEMI: ST-segment-elevation myocardial infarction; NSTEMI: non-ST-segment-elevation myocardial infarction; LM disease: left main coronary artery disease 

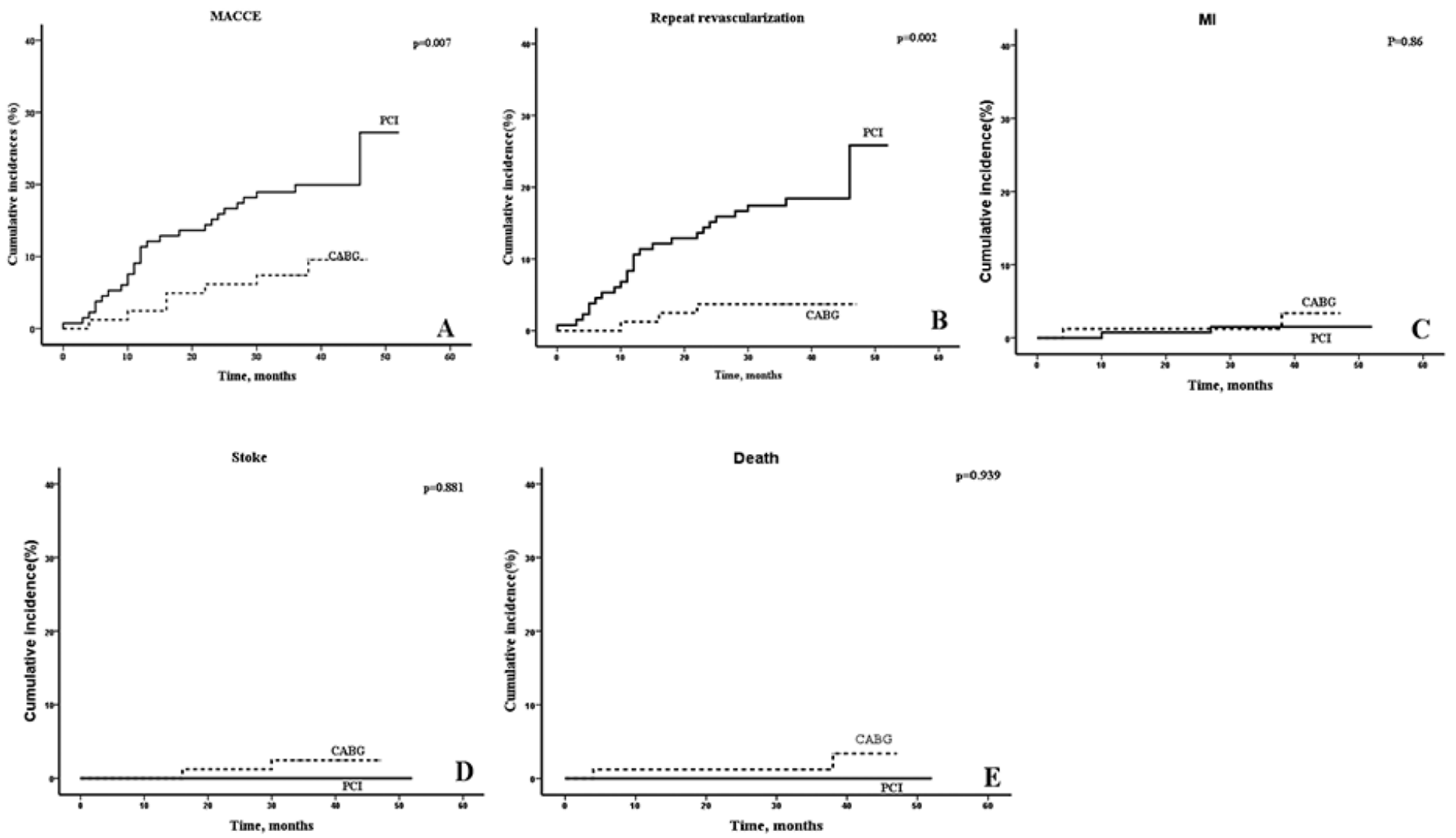

Figure 2

Kaplan-Meier cumulative event curves of MACCE and secondary end points before propensity-score matching. The adjusted risk of $\mathrm{PCl}$ relative to $\mathrm{CABG}$ is shown. PCl: percutaneous coronary intervention; CABG: coronary artery bypass graft; MI: myocardial infarction 

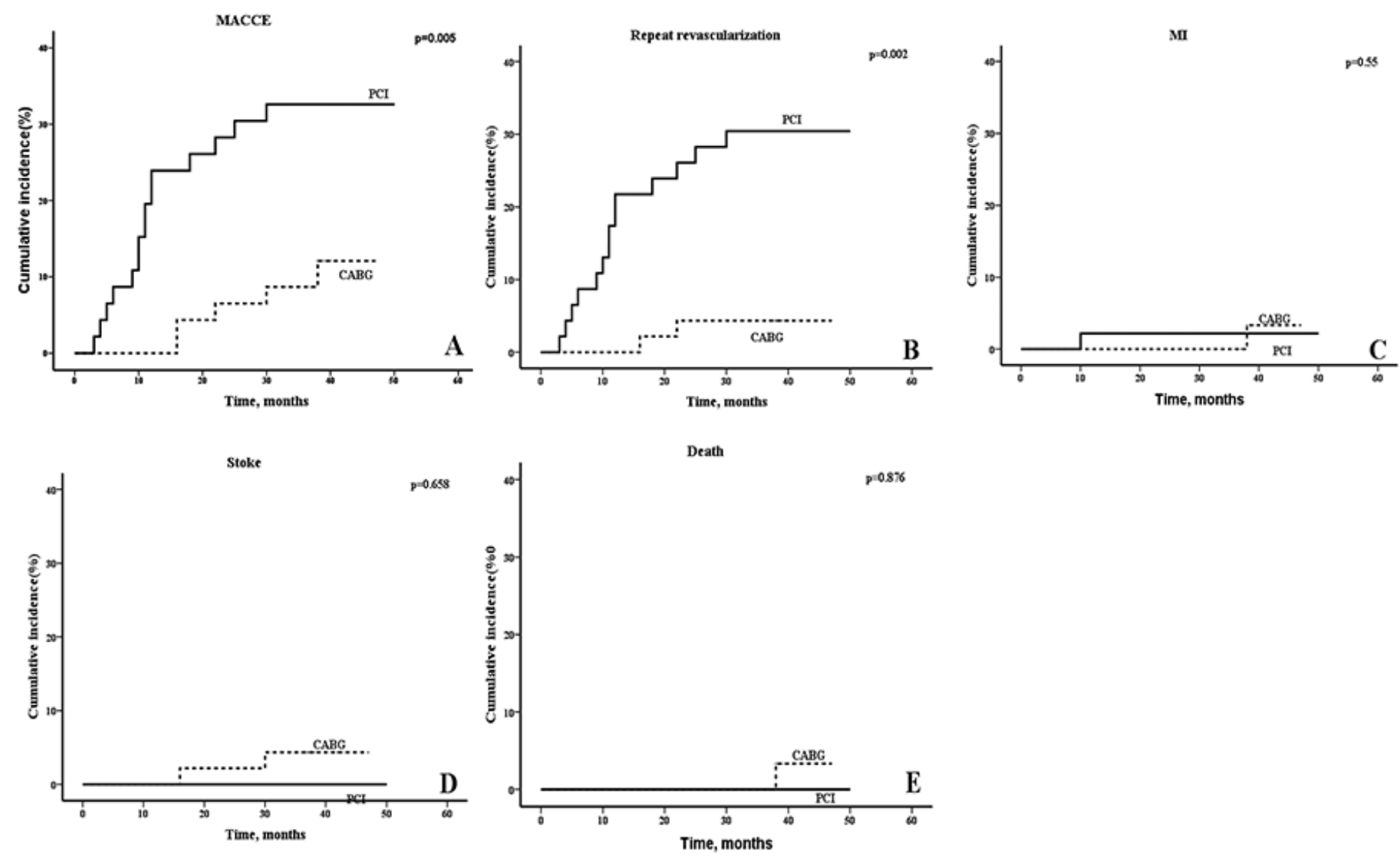

\section{Figure 3}

Kaplan-Meier cumulative event curves of MACCE and secondary end points after propensity-score matching. The adjusted risk of $\mathrm{PCl}$ relative to $\mathrm{CABG}$ is shown. $\mathrm{PCl}$ : percutaneous coronary intervention; CABG: coronary artery bypass graft; MI: myocardial infarction 


\begin{tabular}{|c|c|c|c|c|}
\hline Subgroup & Events/total number & & HR $(95 \%$ CI $)$ & $p$ for interaction \\
\hline \multicolumn{5}{|l|}{ Sex } \\
\hline Women & $2 / 16$ & $*$ & $11899.479(0.005-30715362593)$ & \multirow{2}{*}{0.919} \\
\hline Men & $32 / 197$ & $0-1$ & $2.928(1.203-7.128)$ & \\
\hline \multicolumn{5}{|c|}{ (2) } \\
\hline Yes & $21 / 123$ & & $8.41(1.829-38.678)$ & \multirow{2}{*}{0.209} \\
\hline No & $13 / 90$ & -1 & $1.325(0.357-4.914)$ & \\
\hline \multicolumn{5}{|l|}{ DM } \\
\hline Yes & $9 / 57$ & -1 & $2.461(0.371-16.315)$ & \multirow{2}{*}{0.145} \\
\hline No & $25 / 156$ & -1 & $4.577(1.476-14.192)$ & \\
\hline \multicolumn{5}{|l|}{ Prior MI } \\
\hline Yes & $7 / 45$ & 4 & $0.652(0.125-3.397)$ & \multirow{2}{*}{0.031} \\
\hline No & $27 / 168$ & $=$ & $6.048(1.194-18.344)$ & \\
\hline \multicolumn{5}{|l|}{ Peior HF } \\
\hline Yes & $12 / 55$ & $y$ & $0.926(0.226-3.785)$ & \multirow{2}{*}{0.115} \\
\hline No & $22 / 158$ & & $6.672(1.934-23.642)$ & \\
\hline \multicolumn{5}{|l|}{ LM disease } \\
\hline Yes & $7 / 38$ & & $2.695(0.246-29.591)$ & \multirow{2}{*}{0.839} \\
\hline No & $27 / 175$ & 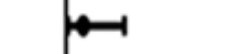 & $3.409(1.268-9.166)$ & \\
\hline \multicolumn{5}{|l|}{ Gensini Score } \\
\hline$<60$ & $13 / 87$ & 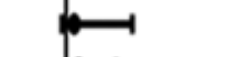 & $2.139(0.444-10.302)$ & \multirow{3}{*}{0.764} \\
\hline \multirow[t]{2}{*}{$>=60$} & $21 / 126$ & 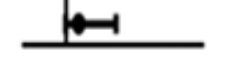 & $2.791(0.973-8.009)$ & \\
\hline & & 505101520 & & \\
\hline
\end{tabular}

Figure 4

Subgroup analysis based on sex, HT, DM, prior MI, prior HF, LM disease and Gensini score HT:

hypertension; DM: diabetes mellitus; MI: myocardial infarction; HF: heart failure; LM disease: left main coronary artery disease, which includes LM coronary artery disease in isolation and LM coronary artery disease with multivessel disease (three-vessel disease); 『: Because the data point is outside the axis limits.

\section{Supplementary Files}

This is a list of supplementary files associated with this preprint. Click to download.

- Additionalfile1.xls

- Additionalfile2.tif 